\title{
XVI.
}

\section{Die Wirkung des Toluylendiamin auf den Thierkörper.}

\author{
Ein Beitrag zur Lehre vom Icterns.
}

(Aus dem Laboratorium der medic. Universitäts-Klinik in Königsberg.)

Von

Dr. Ernst Stadelmann,

Assistenzarzt der Flinik.

II. Theil.

(Fortsetzung von S. 287.)

In dem ersten Theile meiner Arbeit hatte ich die Wirkung des Toluylendiamin auf den Organismus der Hunde geschildert und bewiesen, dass der nach Gaben dieser Substanz auftretende Icterus ein Resorptionsicterus ist. Ich komme nunmehr zu meinen Experimenten an zwei weiteren Thierklassen, den Katzen und Kaninchen, die, wie ich gleich hervorheben will, ein fast entgegengesetztes Verhalten im Vergleich zu den Hunden zeigen und dabei auch untereinander Verschiedenheiten darbieten, die ebenso eigenthümlich wie interessant sind undivor deren Erklärung ich eigentlich ziemlich rathlos dastehe. War bei den Hunden die Regel der Icterus, so sehen wir bei den Katzen ausnahmslos eine ganz kolossale Hämoglobinurie auftreten, während der Icterus zum mindesten sehr zurücktritt, und bei den Kaninchen endlich ist keine Hämoglobinurie, wenigstens für gewöhnlich, vorhanden, aber auch der Icterus ist, wenn auch höchst wahrscheinlich vorhanden, so doch nicht mit unzweifelhafter Sicherheit nachweisbar. Die Einzelheiten dieser Thatsachen und die Beweise für meine Ansicht werden sich aus der detaillirten Schilderung der einzelnen Versuche ergeben.

Experiment No, 1. Eine Katze bekommt 0,2 Toluylendiamin in Milch. Sie frisst das meiste auf. Am nächsten Tage ist sie entchieden krank, frisst wenig, liegt matt und theilnahmlos im Käfig, der Urin ist. dunkler als sonst gefärbt, zeigt aber sonst nichts besonders Abnormes. Am Tage darauf, also am dritten Tage, ist der Urin ausserordentlich 
dunkel, sehr stark bluthaltig. Mikroskopisch werden keine Blutkörperchen, aber ansserordentlich viele Tripelphosphate gefunden und amorphe Massen. Beim Kochen und Ansäuern fällt eine sehr reichliche, flockige, schmutzig braune Masse aus. Heller'sche Blutprobe ergibt ein sehr exquisites Resultat. Spectroskopisch ist ein sehr dunkler, ziemlich breiter Streifen in Grün im unverdünnten Urin sichtbar. Das Thier ist sehr matt und elend, frisst nichts, hat starken Speichelfluss.

Am nächsten Tage ist der Urin schon weniger bluthaltig, zeigt im Uebrigen dasselbe Verhalten.

Am 5. Tage beginnt der Urin schon ganz normal zu werden, es werden im Urin keine abnormen Bestandtheile mehr bei der mikroskopischen Untersuchung gefunden, keine Epithelien und Cylinder, sehr seltene amorphe Massen.

Am 7. Tage ist das Thier wieder vollkommen munter, zeigt in seinem Verhalten absolnt nichts Abnormes, es wird noch 8 Tage beobachtet und dann zu anderen Zweeken verwandt. Icterus konnte in der ganzen Zeit an den Skleren mit Sicherheit nicht constatirt werden.

Experiment No. 2. Eine grosse schöne Katze, deren Urin vollkommen normal ist, keine Gmelin'sche Reaction gibt und auch auf $\mathrm{Zu}$ satz von Methylviolett keinen Farbenumschlag erkennen lässt, bekommt am 21. IV. Vormittags $12 \mathrm{Uhr} 0,3$ Toluylendiamin per Os. Das Thier wird danach sehr unruhig, frisst nicht, ist am 22. Morgens todt und kalt.

Section: An den Geweben ist kein Icterus zu constatiren, an den Nieren punktförmige Ekchymosen, das Parenchym sehr blutreich und triibe. Die Leber sieht nicht gerade abnorm aus, ist sehr blut-und gallenreich. Darminhalt ausserordentlich stark gallenfarbstoffhaltig, die Galle in der sehr prall gefiullten Gallenblase ist normal, Ductus choledochus vollkommen durchgängig, die Darmschleimhaut zeigt nicht die mindeste Injection. Die übrigen Organe sind normal, die Harnblase leer. Mikroskopisch ist abermals wenig zu constatiren. Die Leberzellen sind sehr schön erhalten, haben meistens 2-3 Kerne. Das Organ ist sehr blutreich.

Experiment No. 3, den 11. X. Eine grosse, schöne, schwarze Katze wird in einen Käfig gesetzt und der Urin aufgefangen. Derselbe ist klar, ohne Albumen, neutral-schwach alkalisch, ergibt mit Methylviolett keine Farbenveränderung, Gmelin'sche Reaction ist resultatlos; Spec. Gew. 1026. 50 C.-Ctm. werden auf Gallensäuren verarbeitet, I.

Den 13. X. Urin eiweissfrei, mit Methylviolett keine Farbenveränderung, Gmelin'sche Reaction ohne Resultat, Katze hat etwas Durchfall. 50 C.-Ctm. werden auf Gallensäuren verarbeitet, II.

Die Urinuntersuchungen werden täglich vorgenommen und ergeben nie etwas Abnormes. Auch zeigt das Thier im Uebrigen vollkommen normales Verhalten.

Den 22. X. Mittags bekommt die Katze 0,25 Toluylendiamin in Milch und Fleisch. Den 23. X. ist sie lange nicht so munter wie früher, würgt stark, doch kommt es nicht zum Brechen, an den Skleren kein Icterus. Der Urin sieht dunkel aus, gibt mit Methy்lviolett schönen Farbenumschlag, während Gmelin'sche Reaction resultatlos bleibt. Der Urin ist stark 
alkalisch, ohne Albumen, ausserordentlich schwer (weit über 1060). 30 C.-Ctm. auf Gallensäuren verarbeitet, III.

Den 24. ist die Katze wieder munter, der Urin heller, sieht nicht icterisch aus, mit Methylviolett nur Farbenveränderung, Urin stark alkalisch, ohne Albumen, spec. Gew. 1038; 30 C.-Ctm. werden auf Gallensäuren verarbeitet, IV. An den Skleren kein deutlicher Icterus.

Den 24. Abends wird ein Urin gelassen, der ansserordentlich dunkel und wie lackfarbenes Blut aussieht. Verdinnt man ihn, so nimmt er eine burgunderrothe Farbe an und ist fast ganz klar und durchsichtig. Beim Kochen und Ansäuern fällt ein reichlicher, schmutzigbrauner Niederschlag aus, und der Urin wird dann ganz hell, schwach gelblich gefärbt. Reaction neutral-schwach sauer. 30 C.-Ctm. auf Gallensäuren, V.

Mikroskopisch findet man neben ziemlich reichlichen Tripelphosphaten sehr reichliche detritusartige Massen, die fast ganz aus mehr minder grossen, hellen, glänzenden, ins Grünliche' schimmernden Körnchen oder Kügelchen zusammengesetzt sind. Einzelne dieser Kugeln sind in der Grösse von Blutkörperchen und sehen wie gequollene Blutkörperchen aus, dagegen sind unveränderte Blutkörper nicht aufzufinden.

Den 25. Morgens wird ein Urin gelassen, der ganz ebenso wie der vorige, d. h. wie nur wenig verdünntes dunkles Blut aussieht. Reaction sauer. Die Katze ist furchtbar elend, ist so matt, dass jeden Augenblick der Tod erwartet wird. An den Skleren zweifelhafte Gelbfärbung. Auch hier in diesem Urine fallen beim Kochen und Ansäuern reichliche schmutzigbraune Massen aus. $30 \mathrm{C}$.-Ctm. werden auf Gallensäuren verarbeitet, VI.

Mikroskopisch im Ganzen der vorige Befund, nur werden heute nicht so ganz selten deutlich ausgelaugte, blasse, scheibenförmige und wenig veränderte Blutkörperchen gefunden.

Abends ein ähnlicher Urin mit denselben mikroskopischen und chemischen Befunden, spec. Gew. 1033, stark alkalisch. 30 C.- Ctm. auf Gallensäuren verarbeitet, VII.

Im Spectralapparat sind in diesem Urine wie in den letzten 3 vorhergehenden sehr deutliche Streifen des Hämoglobin wahrnehmbar.

Den 26. Morgens sehr bluthaltiger Urin mit denselben mikroskopischen und chemischen Befunden. Spec. Gew. 1036. Im Spectralapparat die 2 Streifen des Hämoglobin. Die Katze ist sehr elend, scheint sich aber zu erholen, sie frisst noch immer nichts. An den Skleren entschieden etwas icterische Verfärbung. $30 \mathrm{C.}$-Ctm. werden auf Gallensäuren verarbeitet, VIII.

Abends kein Urin.

Den 27. X. Die Hämoglobinurie hat plötzlich aufgehört. Der Urin ist klar, ohne Albumen, sieht wenig icterisch aus, zeigt keine Farbenveränderung mit Methylviolett. An den Skleren ist dagegen eine geringe icterische Verfärbung mit Sicherheit zu constatiren. Die Katze ist munterer, frisst schon etwas. Spec. Gew. des sauer reagirenden Urins 1037. 30 C. Ctm. werden anf Gallensäuren verarbeitet, IX.

Den 28. Urin normal, ebenso den 29. und 30.

Die Katze hat sich vollkommen erholt, nur sieht sie noch recht mager aus. Sämmtliche Untersuchungen auf Gallensäuren geben negatives Resultat. Der Versuch wird abgebrochen. 
Experiment No. 4. Den 22. XI. Abends 6 Uhr werden einer kräftigen, mittelgrossen schwarzen Katze, deren Urin mehrmals untersucht, keine Abnormitäten darbot, 0,11 Toluylendiamin hypodermatisch beigebracht. Den 23. Morgens ist das Thier vollkommen munter, frisst ziemlich viel, zeigt nicht das geringste Unbehagen. Der Urin des heutigen Tages zeigt nichts Abnormes. Im Laufe des Tages wird noch einmal Urin gelassen, der etwas dunkelgelb aussieht, mit Methylviolett Farbenumschlag gibt, jedoch gelingt die Gmelin'sche Reaction nicht. An den Skleren nichts Abnormes.

Den 24. Morgens 9 Uhr wird ein Urin aufgefangen, der ebenfalls keine Abnormitäten zeigt, nicht deutlich icterisch ist, wenn er auch etwas dunkelgelb gefärbt ist. Mit Methylviolett tritt geringe Farbenveränderung auf, Gmelin'sche Reaction resultatlos. An den Skleren zweifelhafte, jedenfalls sehr geringe icterische Verfärbung. Das Thier ist sehr munter, springt herum, schnurrt, gibt nicht das geringste Zeichen von Unbehagen za erkennen. Da wird um 10 Uhr Morgens ein Urin gelassen, welcher wie in dem vorigen Falle so ausserordentlich stark bluthaltig ist, dass man verdünntes Blut vor sich zu haben wähnt. Mikroskopisch wird in dem Urin eine Menge von Tripelphosphaten gefunden, daneben recht reichliche, schmutzig-roth gefärbte Massen, keine Zellen, keine Blutkörperchen.

Den 25. XI. Ueber Nacht und heute Morgen wieder ausserordentlich blutig gefürbter Urin. Mikroskopisch finden sich ansser sehr reichlichen Tripelphosphaten und den gelben Körnern und Detritushaufen keine weiteren abnormen Bestandtheile, besonders keine unzweifelhaften Blutkörperchen.

Im Laufe des 25. und 26. werden noch wiederholt ähnliche Urine mit demselben mikroskopischen und chemischen Verhalten entleert. Meistens reagiren die einzelnen Urinmengen sauer. Hin und wieder ergibt die mikroskopische Untersuchung einige seltene ausgelaugte Blutkörperchen. Die Katze, welche während der ganzen Zeit nichts frisst, ist ausserordentlich matt, kann ohne Schwanken kaum stehen, scheint aber sich sonst im Ganzen wohl zu befinden, wenigstens schnurrt sie, sobald man sie streichelt. An den Skleren ist Icterus mit Sicherheit nicht zu entdecken, die Skleren sehen ganz weiss, ausserordentlich anämisch aus.

Den 26. beginnt die Hämoglobinurie wieder nachzulassen, die corpusculären Bestandtheile, Blnt- und Eiterkörperchen, werden häufiger, während die Kugeln and Detritusmassen sehr abnehmen. Die Katze beginnt anch wieder etwas zu fressen. Skleren und Zahnfleisch ganz weiss und blutleer, die Stimme heiser, aphonisch.

Den 27. Der über Nacht entleerte Urin enthält nur noch sehr wenig Hämoglobin, etwas reichlicher Albumen, reagirt sauer. Katze erholt sich rasch, zeigt ausserordentlichen Appetit, ist bald ganz so munter, als ob nichts mit ihr geschehen wäre.

Sämmtliche Urinproben, die bis zum 28. entleert wurden, es sind deren XIII, werden einzeln auf Gallensäuren untersucht, jedoch mit vollständig negativem Erfolge.

Experiment No. 5. Eine ziemlich grosse, schwarze Katze wird zur Untersuchung verwandt. 
Den 4. I. Urin klar, schwach sauer, beim Kochen und Ansänern fällt kein Albumen aus, Gmelin'sche Reaction resultatlos, mit Methylviolett keine Farbenveränderung. Spec. Gew. 1035.

Den 5. I. Urin klar, ohne Albumen, schwach alkalisch, nicht gallenfarbstoff haltig.

Den 7. I. Urin vollkommen normal.

Abends gegen 7 Uhr bekommt sie 0,11 Toluylendiamin subcutan.

Den 8. ist der Urin trübe, leider mit Koth etwas verunreinigt, jedenfalls aber frei von Albumen. Die Katze ist munter, gibt nur Zeichen des Wohlbefindens von sich, frisst gut. Gewebsicterus ist nicht zu. entdecken.

Den 8. Abends. Vollkommen normaler Urin, ohne Albumen, mit Methylviolett ganz geringe Farbenveränderung. Gmelin'sche Reaction resultatlos.

In der Nacht vom 8-9. sind ungefahr 30 C.-Ctm. eines ausserordentlich stark bluthaltigen, leider durch Koth etwas verunreinigten Urins gelassen worden. Mikroskopisch finden sich in demselben neben Verunreinigungen durch die Fäcalmassen ausserordentlich massenbafte Bakterien, sehr zahlreiche Tripelphosphate und unzweifelhafte, wenig veränderte, wenn auch seltene Blutkörperchen, häufiger jedoch gequollene und stark veränderte, die ihre Scheibenform verloren haben. Spectroskopisch bei erheblicher Verdïnnung deutliche Hämoglobinstreifen.

Um $10 \mathrm{Uhr}$ wird wieder ein sehr stark bluthaltiger, schwach alkalischer Urin gelassen, welcher ganz rein aufgefangen werden kann und das Anssehen einer starken, reinen Hämoglobinlösung hat. Mikroskopisch können neben Phosphaten und geringen amorphen Massen (keine Cylinder) massenhafte glänzende, das Licht stark brechende Körnchen und Kügelchen von verschiedener Grösse aufgefunden werden, die oft genal so wie gequollene rothe Blutkörperchen anssehen, und die ich entschieden für veränderte resp. zerfallene Blutkörperchen erklären möchte. Aether ist auf diese Kugeln einflusslos. Der wunderschöne, rothbraune, klare Urin gibt in unverdiinntem Zustande spectroskopisch untersucht Folgendes: Das ganze Spectrum wird von rechts her bis zum Gelbroth vollkommen absorbirt, und in dem erhaltenen Rothgelb sieht man bei $\mathrm{C}$ einen sehr deutlichen, nicht breiten Absorptionsstreifen, den des Hämatin. Verdünnt man die Lösung immer mehr, so wird das Spectrum immer breiter, der Hämatinstreifen immer blasser und undeutlicher, dagegen treten nun die 2 Streifen des Hämoglobin zwischen $\mathrm{D}$ und $\mathrm{E}$ sehr deutlich hervor.

Um 1 Uhr etwa wird die Katze ohne Narkose durch Verbluten getödtet, dabei entleert sie einen ebenfalls rothbraun aussehenden Urin in reichlicher Menge, der nicht weiter untersucht wird. Das Blut, welches direct aus der Carotis mittelst einer Canüle in eine Porcellanschale entleert wird, sieht fast ebenso aus wie der Urin, d. h. rothbraun, dunkel, mehr lackfarben. Es wird sofort defibrinirt, wobei sich verhältnissmässig wenig Fibrin ausscheidet, und sofort mikroskopisch und auf Gallensäuren untersucht. Eine Probe des Blutes wird centrifugirt, und bleibt, nachdem sich die Blutkörperchen abgesetzt haben, ein stark hellrothes, klares durchsichtiges Serum zurück. Es ist schon makroskopisch klar, dass hier in dem Serum Hämoglobin in bedentender Menge in Lösung ist. 
Das Serum wird nun vorsichtig abgehebert und untersucht. Mikroskopisch finden sich $_{i}$ zwar noch Blutkörperchen in ihm, aber ausserordentlich wenig und diese können unmöglich das blutige Aussehen des Sernms bedingt haben.

Spectroskopisch zeigt es dasselbe Verhalten wie der Urin, d. h. unverdiunnt gibt es bei sehr stark absorbirtem Spectrum den Sireifen des Hämatin, mehr verdünnt einen undeutlichen Hämatinstreifen und immer deutlicheren Hämglobinstreifen. Die am Boden des Gefässes nach dem Centrifugiren liegenden Blutkörperchen sind natürlich sehr zusammengedrängt, klein, etwas geschrumpft, zeigen aber sonst nichts Bemerkenswerthes. Das aus der Carotis entleerte frisch untersuchte Blut zeigt mikroskopisch etwas geschrumpfte Blutkörperchen, die oft lang gestreckt aber sehr selten in Geldrollenform liegen, spectroskopisch in möglichst concentrirter Form den Hämatinstreifen, aber lange nicht so dentlich wie in dem Serum des centrifugirten Blutes, später, d. h. in verdünnterem Zustande untersucht, natürlich âuch die Hämoglobinstreifen.

Die Section des Thieres ergibt an den Skleren nicht vollkommen deutliche icterische Verfärbung, dagegen deutlichen Icterus der Haut und des Unterhautzellgewebes. Die Eingeweide sind nicht deutlich icterisch gefärbt. Lunge, Herz normal, Leber sieht sehr gelb und gallenreich aus. Gallenblase und Ductus choledochus nebst Ductus cysticus stark mit Galle gefüllt. Im Darm sehr reichliche gallig gefärbte Massen, von einem Katarrh der Darmschleimhant keine Spur. Die Leber ist durch den Reichthnm an verändertem braunen Blute mehr gelblichbraun gefärbt, beim Durchschnitt durch dieselbe entleert sich iiberall aus den grösseren Gallengängen ausserordentlich reichliche Galle. Die Nieren sehen ebenso braun aus, zeigen auf dem Durchschnitt nichts $\Delta$ bnormes. In dem Fettgewebe lose ins Abdomen hineinhängend, nur durch einen dünnen, soliden Strang befestigt, befindet sich ein etwa 50 pfennigstückgrosser, nicht besonders dicker brauner Tumor, der auf dem Durchsehnitt braun und gekörnt aussieht, er ist mässig weich und ähnelt einem alten organisirten Coagulum.

Die mikroskopische Untersuchung an frischen Präparaten ergibt in dem Tumor Unmassen von Blutkörperchen und zerfallenen Zellen, sonst nichts. Zellen der Nieren und Leber stark aber fein gekörnt.

Schnittpräparate an den erhärteten Objecten ergeben Folgendes: Die Leberschnitte geben in Hämatoxylin eine sehr ungleichmässige Fürbung, ebenso bei Carmintinction. Grosse Abschnitte haben sich sehr schlecht gefärbt und heben sich mit gelber Farbe von den gut tingirten rothen Partien ab. Diese Gelbfärbung ist wohl unzweifelhaft dureh Gallenfarbstoff bedingt, der in erheblicher Menge im interstitiellen Gewebe abgelagert ist, und dessen krystallinische Natur man manchmal unzweifelhaft feststellen kann. $\mathrm{Ob}$ er auch in den Zellen selbst und nicht nur im interstitiellen Gewebe liegt, ist allerdings nicht mit Sicherheit festzustellen.

Die Blutgefässe sind sehr gefullt. Verfettung im eigentlichen Sinne des Wortes besteht nicht, die Leberzellen sind fein gekörnt, grobe Körner, die man als Fetttropfen ansprechen könnte, werden ganz vermisst. Dagegen findet sich massenweise und nicht sehr ausgedehnt nicht in diesem Falle, sondern in einigen anderen ähnlichen, die ich gleichfalls nntersuchte, eine nicht ganz unerhebliche Fettankäufung. Nach meiner Erfahrung 
finden sich derartige Fettnester aber auch normalerweise in der Katzenleber, und würde selbst eine stärkere Verfettung anderer Organe es mir nicht erlauben, bei der bestehenden kolossalen Anämie der Thiere irgend welche Rückschlüsse zu machen. Nirgends treten Spuren einer Entzündung im interstitiellen Gewebe auf.

Die Nieren geben im Ganzen dasselbe Resultat wie die Leber. Die Zellen sind etwas trïbe, feingekörnt, Kerne aber fast ïberall deutlich, keine Fetteinlagerung. In den Harnkanälchen keine Cylinder oder Blutkörperchen, keine Spur einer etwaigen Entzündung. Dagegen findet man ziemlich reichliche Blutkörperchen im interstitiellen Gewebe und in den Glomerulis, und zwar hier an den Rändern der Schlingen, d. h. besonders an der Oberfläche der Glomeruli, an der Grenze der Bowman'schen Kapsel. In dieser selbst sind aber niemals mit Sỉcherheit Blutkörperchen zu entdecken.

Milz scheint sehr blutreich, sonst normal.

Der Tumor zeigt sich in Schnitten als fast allein ans Blutkörperchen zusammengesetzt, die durch ein seltenes Bindegewebe, in welchem spärliche Blntgefässe verlaufen, zusammengehalten werden. Daneben finden sich sehr reichliche Hämatoidinkrystalle.

Ich habe diesen Sectionsbefund hier so ausführlich angegeben, um mich dadurch hinfort der. Verpflichtung ïberhoben zu sehen, auch beì den übrigen Sectionen, die ganz genau dieselben Resultate lieferten, eine genauere Schilderung der Befunde zu machen.

Die Untersuchung der einzelnen Urinproben uud auch des Blutes auf Gallensäuren gibt vollkommen negatives Resultat. Auch Gallenfarbstoff ist mit Sicherheit nicht durch die Gmelin'sche Reaction in den enteiweissten Urinen nachzuweisen.

Experiment No. 6. Einer mittelgrossen Katze werden, nachdem vielleicht eine Woche lang der Urin beobachtet und auf Gallensäuren untersucht worden ist, am 18. V. Abends 7 Uhr 0,11 Toluylendiamin hypodermatisch beigebracht.

Den 19. Morgens ist der Urin dunkel, gelblichgrün gefärbt, scheint Gallenfarbstoff zu enthalten, jedoch gelingt die Gmelin'sche Reaction nicht deutlich, wohl aber gibt Methylviolett eine bedeutende Farbenveränderung. Die Katze ist matt, elend, frisst wenig. An den Skleren kein Icterus. 30 C.-Ctm. werden auf Gallensäuren verarbeitet, I.

Nachmittags 2 Uhr wird ein weniger gefärbter aber auch grünlich aussehender Urin entleert, bei welchem Gmelin'sche Reaction ebensowenig gelịngt, den auch Methylviolett unverändert lässt. Die Katze ist elend, frisst nicht. An den Skleren keine Veränderung. 30 C.-Ctm. auf Gallensäuren untersucht, II.

Den 20. Morgens 8 Uhr wird, nachdem über Nacht kein Urin gelassen worden war, ein sehr dunkelrother, klarer Urin entleert, der unzweifelhaft stark hämoglobinhaltig ist. Beim Kochen und Ansäuern fällt eine mässig reichliche, schmutzigbraune, flockige Masse aus. Reaction sauer. Er wird auf Gallensäuren verarbeitet, III. 
Um $12 \mathrm{Uhr}$ wird ein ausserordentlich stark bluthaltiger Urin entleert, der wie verdünntes Blut aussieht, stark alkalisch reagirt und einen eigenthümlichen sehr aromatischen Geruch hat. Reaction stark alkalisch. Er wird auf Gallensäuren verarbeitet, IV.

Um 2 Uhr wird die Katze durch Entbluten aus der Carotis getödtet. Das Blut sieht sehr braun aus, so dass die Arterien nicht mehr als rothe, sondern als blasse, etwas braun gefärbte Stränge durchscheinen. Mikroskopisch zeigen sich die Blutkörperchen entschieden verändert. Die meisten sind klein, blass, unregelmässig geschrumpft, liegen oft $\mathrm{zu} 6-8$ auf einem Haufen unregelmässig, nicht in Geldrollenform zusammen, daneben finden sich recht viele zu Grunde gehende, blasse Blutkörperchen, sehr viele Körnchenmassen. In der Harnblase findet sich gleichfalls sehr stark bluthaltiger Urin, der auch auf Gallensäuren verarbeitet wird, V.

Die mikroskopische Untersuchung der einzelnen Urinproben ergibt bei allen (d. h. III, IV und V), am meisten bei III sehr viele kleine Körnchen und Kugeln wie schon in den früheren Fällen; daneben hin und wieder grössere Kugeln, die entschieden veränderte Blutkörperchen sind, ihre Scheibenform aber verloren haben und das Licht ziemlich stark brechen. Sonst ist im Urin wenig Abnormes aufzufinden, keine Cylinder, keine abnormen Krystallformen.

Spectroskopisch ergibt jeder der Urine III, IV und V sehr starke Hämoglobinstreifen in entsprechender Verdünnung und daneben auch bei geringerer Verdünnung einen schönen Hämaținstreifen, bei III ist der letztere nur angedentet.

Die Section ergibt als hervorragendste Resultate eine nicht hochgradige aber dentliche icterische Verfärbung der Skleren, der Haut, des Fettgewebes. Leber sehr braun, stark blut- und gallehaltig. Gallenblase und Ductus choledochus sind sehr prall gefüllt. Ansmïndung des Ductus in den Darm vollkommen frei. Die übrigen Resultate, auch die mikroskopische Untersuchung, entsprechen dem vorigen Falle.

Das Blut wird centrifugirt. In dem klaren Serum sehr reichliches Hämoglobin, welches spectroskopisch nachgewiesen wird, ebenso eine bedeutende Menge von Hämatin. Der Rest des Blutes wird auf Gallensäduren verarbeitet und werden weder in ihm noch in den einzelnen Urinportionen auch nur Spuren derselben gefunden.

Experiment No. 7. Eine grosse weisse Katze wird den 14. XII. in den Käfig gesetzt. Am 15. ist der Urin normal, trotzdem das Thier seit 24 Stunden nichts gefressen hat.

Den 16. XII. Katze hat bis heute noch nichts gefressen. Der Urin ist sehr dunkel, gibt keine- unzweifelhafte Gmelin'sche Reaction. Der Urin wird täglich bis zum 30 . untersucht, ohne dass jemals Gallenfarbstoff in demselben nachgewiesen werden konnte. Unterdessen ist die Katze ganz zutraulich geworden und frisst reichlich von dem ihr verabreichten Fressen.

Den 30. um 12 Uhr erhält sie 0,02 Toluylendiamin subcutan.

Den 31. kein Urin, Katze zeigt nichts Abnormes, frisst wie sonst; Nachmittags um 3 Uhr dunkler, klarer Urin, der kein Blut 'enthält, kein Albumen; Gmelin'sche Reaction misslingt. 
Den 1. I. Katze ganz munter, an den Skleren nichts Abnormes, Urin normal, ebenso in den folgenden Tagen.

Am 2. I. erhält sie um $12^{1 / 4}$ Uhr 0,26 Toluylendiamin subentan.

Nachmittags wenig, ziemlich normal aussehender Urin, in welchem unreine Salpetersäture einen schwachen aber deutlichen grünen Ring gibt. Der Urin enthält entschieden etwas, wenn auch nur sehr wenig Gallenfarbstoff. Die Reaction tritt übrigens erst nach einiger Zeit auf.

Den 8. wird kein Urin entleert. An den Skleren undeutliche Gelbfärbung. Katze sehr elend, frisst absolut nichts.

Den 9. Morgens wird das Thier todt gefunden.

Section: An den Skleren schwache aber unzweifelhafte Gelbfärbung, gleichfalls schwacher Icterus des Unterhautzellgewebes. In der Blase absolut kein Urin. Blut stark braun; unzweifelhafter sehr starker Icterus der Leber. Dieselbe ist gross, die grossen Gallengänge sind sehr prall mit gelbgrünlicher Galle gefüllt, ebenso die Gallenblase. In den Pleuren beiderseits mässig reichliche, stark icterische klare Flüssigkeit, die nicht bluthaltig ist und sehr schöne Gmelin'sche Reaction ergibt. Die mikroskopischen Befunde sind die alten.

Experiment No. 8. Den 17. XII. bekommt eine schwarze Katze, deren Urin seit mehreren Tagen untersucht und normal befunden worden war, um 11//4 Uhr 0,11 Toluylendiamin subcutan.

Den 18. Abends wird der erste Urin entleert, derselbe ist sehr dunkel, gibt keine Gmelin'sche Reaction, während Methylviolett vollkommenen Farbenumschlag ergibt. Die Katze ist munter, frisst gut.

Am 19. kein Urin, an den Skleren kein Icterus.

Den 20. Morgens zweiter Urin, sehr dunkel, trübe, bluthaltig, Urin ist alkalisch, enthält mikroskopisch die schon häufig geschilderten Bestandtheile. An den Skleren nichts Abnormes.

Den 21. Morgens dritter Urin, welcher sehr dunkel, icterisch aussieht. Gmelin'sche Reaction gelingt jedoch nicht, während Methylviolett starken Farbenumschlag ergibt. Urin deutlich alkalisch, ohne Albumen. An den Skleren kein deutlicher Icterus. Katze hat starken Durchfall von sehr gallig gefärbten Massen.

Den 22. Morgens vierter Urin, sieht normal aus, ergibt keine Gmelin'sche Reaction, mit Methylviolett starker Farbenumschlag, schwach alkalisch, ohne Albumen. Skleren normal, Katze munter.

Den 22. um $12^{1 / 2}$ Uhr 0,11 Toluylendiamin subcutan, nachdem kurz vorher noch ein vollkommen normaler Urin entleert worden war.

Den 23. Morgens sehr dunkler Urin, der eine Spur Albumen enthält, keine Gmelin'sche Reaction ergibt, ohne Hämoglobin.

Den 24. Morgens ein sehr dunkler, stark bluthaltiger Urin, der stark alkalisch, die bekannten mikroskopischen Bestandtheile enthält. Das Thier selbst ist munter, frisst gut, an den Skleren ansser Anämie nichts Abnormes, starker Durchfall, bei welchem sehr gallenhaltige Massen entleert werden. Spectroskopisch die Streifen des Hämoglobin und sehr schwach Streifen des Hämatin.

Den 25. Morgens ähnlicher Urin, stark alkalisch, mit denselben mikroskopischen und chemischen Befunden. 
Den 26. normaler Urin, enthält kein Hämoglobin mehr. Um 11/1/2 Uhr werden dem Thiere 0,16 Toluylendiamin hypodermatisch beigebracht. An den Skleren kein Icterus.

Den 27. wird wieder, nachdem in der Nacht kein Urin entleert worden war, ein exquisit bluthaltiger Urin gelassen, der unzweifelhaft ziemlich reichliche ausgelaugte Blutkörperchen enthält und daneben die bekannten Körner und Kugeln. Reaction deutlich alkalisch, Thier sehr matt und elend. An den Skleren schwache, entschieden schmutzig gelbbraune Verfärbung. Erheblicher Durchfall. Der enteiweisste Urin gibt keine Gmelin'sche Reaction.

Den 28. wird in der Nacht und um 10 Uhr Morgens ein ähnlicher Urin entleert mit den alten Befunden. An den enteiweissten Urinen gelingt keine Gmelin'sche Reaction, während Methylviolett einen starken Farbenumschlag ergibt. An den Skleren keine unzweifelhafte Verfärbung mehr.

Den 29. ziemlich normaler Urin, an dem die Gmelin'sche Reaction nicht gelingt, wäbrend Methylviolett vollkommenen Farbenumschlag ergibt.

Den 30. ist die Katze recht munter, zeigt keine Abnormitäten mehr, keinen Icterus an den Skleren, keinen Gallenfarbstoffgehalt des Urins. Um $12^{1 / 2}$ Uhr werden ihr 0,26 Toluylendiamin subcatan beigebracht.

Den 31. Morgens werden etwa 30 C.-Ctm. eines sehr dunkeln aber nicht bluthaltigen Urins entleert, der kein Albumen enthält. Methylviolett ergibt vollkommenen Farbenumschlag, Gmelin'sche Reaction einen sehr exquisiten grünen und violetten Ring. An den Skleren geringe, rein gelbe Verfärbung. Katze sehr elend, frisst nichts.

Den 1. Morgens sehr reichlicher kolossal blatiger Urin. An den Skleren sehr starker, unzweifelhafter Icterus. Katze sehr matt. Die mikroskopische Untersuchung des Urins ergibt die bekannten Körper in demselben. Gmelin'sche Reaction erzielt nach dem Enteiweissen ein sehr schönes Resultat, mit Methylviolett vollkommener Farbenumschlag.

Den 2. II. kein Urin, Katze hat sich etwas erholt, frisst gierig, ist sehr abgemagert. Icterus ist etwas schwächer an den Skleren, die Gelbfärbung derselben hat einer mehr schmutzigbrannen Farbe Platz gemacht.

Den 3. II. kein Urin, an den Skleren ist der Icterus noch schwächer geworden. Katze sehr schwach.

Um 121/2 Uhr wird wieder ein ausserordentlich bluthaltiger Urin entleert, der sehr trübe, verhältnissmässig sehr viele Blutkörperchen enthält, die allerdings meistens stark verändert sind. Daneben seltene Cylinder und Körnchenhaufen, massenhafte Mikrokokken, die ich auch in den übrigen selbst ganz frischen Urinen auffallend häutig gefunden habe. Nach dem Enteiweissen wird die Gmelin'sche Reaction mit negativem Erfolge angestellt, Methylviolett ergibt vollkommenen Farbenumschlag.

Den 4. Morgens ist die Katze todt.

Section: Die Blase ist angeftillt mit bräunlichgelbem: Urin, der anfangs aus derselben klar abläuft, später jedoch entleeren sich grosse Stücke schwarzer und schwarzbrauner Massen. An den Skleren etwas schmutziggelbbraune Verfärbung, starke Anämie. Fettgewebe und Unterhautzellgewebe sehr wenig icterisch gefärbt. Icterus der Leber und der Niere. In der Leber sehr viel Galle. Gallengänge stark geschlängelt, 
nicht sehr gefüllt. Einzelne Partien der Niere haben eine blauschwarze Farbe, die am nächsten Tage sehr nachgelassen hat. Im Allgemeinen sieht die Niere sehr buntscheckig aus. Das ganze pericardiale und $\mathrm{Me}$ diastinalgewebe ist sulzig, mit icterischer, klarer Flüssigkeit infiltrirt. In dem Darm ausserordentlich gallehaltige Massen. Im Uebrigen möchte ich nur noch hervorheben, dass die Leber des ausserordentlich fetten Thieres sehr viel Fett enthielt. Dieses Fett liegt auch hier nesterweise in den Zellen, dieselben fast ganz mit einem grossen Tropfen ausfüllend, so dass die Leberzellen Fettzellen ganz ähnlich sind.

Die mikroskopische Untersuchung des Urins und. besonders der beschriebenen dunkeln Massen in ihm ergibt, dass auch sie meistens aus Kugeln, Körnern und Detritus bestehen. Die Gmelin'sehe Reaction ergibt in dem enteiweissten Urin ein unzweifelhaftes Resultat.

Experiment No. 9. Den 12. Ir. werden einer grossen grauen Katze, deren Urin seit dem 19. I. untersucht worden ist, und der in der ganzen Zeit keine Abnormitäten gezeigt hat, trotzdem das Thier öfters mehrere Tage hinter einander nichts frass, 0,21 Toluylendiamin per 0 s in Milch und Fleisch gegeben, wovon kaum etwas verloren geht. Abends um 6 Uhr wird ein Urin entleert, der keine Gmelin'sche Reaction ergibt, mit Methylviolett starker Farbenumschlag.

In der Nacht vom 12-13, recht dunkler Urin, der keine Gmelin'sche Reaction, mit Methylviolett starken Farbenumschlag ergibt. An den Skleren sehr zweifelhafte Gelbfärbung.

In der Nacht vom 13-14. stark bluthaltiger Urin, welcher mikroskopisch die alten Verhältnisse zeigt. An den Skleren keine sichere Gelbfärbung. Im Urin gelingt die Gmelin'sche Reaction nach dem Enteiweissen nicht, mit Methylviolett Farbenumschlag.

Den 14. um 6 Uhr Abends noch stärker bluthaltiger Urin. Nach dem Enteiweissen entsteht auf Zusatz unreiner Salpetersäure ein grüner Streifen, der nach kurzer Zeit verschwunden ist und einem bräunlichenvioletten Platz macht. Der Urin ist sehr diluirt, in dem auf dem Wasserbade concentrirten wird auf Znsatz unreiner Salpetersäure zuerst die ganze Salpetersäure blau, blasst aber von unten herauf sehr ab, so dass nach 5 - 10 Minuten nur noch ein schmaler blaugrüner Ring an der Grenze des Urins vorhanden ist. Schliesslich bleibt ein schmaler grüner Ring und darunter ein violetter.

In der Nacht rom 14-15. sehr stark bluthaltiger Urin, der mikroskopisch und chemisch dasselbe Verhalten wie der vorige zeigt. An den Skleren besteht eine schmutzig bräunlichgelbe Verfärbung.

Den 15. um 12 und 7 Uhr bluthaltiger Urin mit dem gleichen Verhalten.

Den 16. um $7 \mathrm{Uhr}$ Morgens ein eben solcher Urin, in welchem nur ziemlich reichliche ausgelaugte Blutkörperchen aufzufinden sind. Der Hämoglobingehalt des Urins nimmt schon bedeutend ab.

Den 17. 12 Uhr Mittags ein nicht mehr bluthaltiger Urin, in welchem Gmelin'sche Reaction nicht mehr unzweifelhaft gelingt; während in den frïheren Urinen stets ein grïner Ring nach Zusatz unreiner Salpetersäure auftrat. An den Skleren sehr zweifelhafte Gelbfärbung. Dieselbe that fortdauernd entschieden abgenommen. 
In den Urinen bis zum 23. wird kein Gallenfarbstoff mehr gefunden, kein Hämoglobin, kein Albumen. Die Skleren sind ganz normal geworden. Katze vollkommen munter.

Den 23. um 11 Uhr erhält die Katze 0,26 Toluylendiamin per Os in Fleisch und Milch. Am Nachmittage hat die Katze viel miaut, nichts gefressen, häufig Koth gelassen, der jedoch nicht ganz dïnn war.

Den 24. II. Ueber Nacht sehr dunkler Urin, der fast braun aussieht, nicht gerade icterisch, trübe, schwach alkalisch ist. Gmelin'sche Reaction resultatlos, mit Methylviolett vollkommener Farbenumschlag. An den Skleren nichts Abnormes, Katze matt und elend, frisst nichts, speichelt ziemlich stark. Urin ohne Albumen.

Den 24 um 3 Uhr wieder sehr stark bluthaltiger Urin, in welchem nach dem Enteiweissen die Gmelin'sche Reaction sehr schön gelingt.

In der Nacht vom 24-25. ein gleichfalls sehr stark bluthaltiger Urin, der auch nach dem Enteiweissen sehr schöne Gmelin'sche Reaction gibt. An den Skleren ist eine schwache Gelbfärbung sichtbar.

Den 25. um $1 \frac{1}{2}$ Uhr ein weiterer Urin mit dem gleichen Verhalten, der nach dem Enteiweissen sehr schöne Gmelin'sche Reaction ergibt.

Abends 6 Uhr wird ein sehr viel hellerer Urin entleert, der sehr schöne Gmelin'sche Reaction ergibt.

In der Nacht vom 25-26. wenig bluthaltiger, sehr truiber Urin, der unzweifelhafte Gmelin'sche Reaction ergibt. An den Skleren ist die Gelbfärbung noch schwächer.

1 1/2 Uhr Mittags trüber Urin, ohne Hämoglobin, der nach dem Enteiweissen schöne Gmelin'sche Reaction ergibt.

Am 27. um 11 Uhr trüber Urin ohne Hämoglobin, der keine Gmelin'sche Reaction ergibt. An den Skleren sehr zweifelhafte Verfärbung.

Den 28. Am Urin und den Skleren ist nichts Abnormes mehr wahrnehmbar. Katze ganz munter.

Den 1. III. erbält die Katze 0,26 Toluylendiamin per Os in Milch und Fleisch, wovon sie ziemlich Alles auffrisst.

Um 8 Uhr Abends brauner, klarer Urin ohne Albumen, der keine Gmelin'sche Réaction ergibt. Katze hat Durchfall, frisst nichts, hat etwas gebrochen.

In der Nacht vom 1-2. ebenfalls sehr dunkler Uxin ohne Albumen, der keine Gmelin'sche Reaction ergibt, mit Methylviolett vollkommener Farbenumschlag.

Am 2. III. An den Skleren ein schwacher aber unzweifelhafter Icterus. Um 11//2 Uhr entleert die Katze sehr bluthaltigen Urin mit dem bekannten Verhalten.

Um 12 Uhr wird sie durch Verbluten aus der Carotis getödtet.

Section: Sehr starker, unzweifelhafter Icterus der Haut, des Fettgewebes, der Gefässe und auch der Lymphwege. Die Leber ist ausserordentlich icterisch, massenhafte Galle enthaltend. Gallenblase, Ductus choledochus und cysticus sind ganz prall gefillt mit Galle und bedeutend ausgedehnt. Im Darm sehr stark gallig gefärbte Massen, Ductus choledochus vollkommen leicht durchgängig. Im Uebrigen die bekannten Verhältnisse.

In dem centrifugirten Blute ist das Serum sehr stark hämoglobin- 
haltig, ganz klar, ohne Blutkörperchen, jedoch mit einem etwas bräunlichen Schimmer. Spectroskopisch untersucht ergaben sich die Streifen des Hämoglobin sehr deutlich und daneben schwach aber entschieden vorhanden der Streifen des Hämatin zwischen C und D, näher an C, an der Grenze des Gelb gegen Roth. Die Auflösung der Blutkörperchen und die Hämatinbildung hatte bei Weitem noch nicht ihren Höhëpunkt erreicht, denn in den früheren Fällen war der Streifen sehr viel stärker. Das frisch entleerte Blut hatte ein sehr stark bräunlich schmutziges Aussehen und einen ausserordentlich aromatischen Geruch.

Experiment No. 10. Am 12. IV. werden einer kräftigen grauen Katze, die schon vor einiger Zeit zu anderen Experimenten gedient hatte, nunmehr aber absolut keine Abnormitäten mehr darbot, Mittags 121/2 Uhr 0,11 Toluylendiamin in eine Vena jugularis injicirt.

Den 13. Morgens an den Skleren schwache, nicht vollkommen sichere icterische Verf ärbung. Der erste Urin, am 12. Abends entleert, der zweite am 13. Vormittags $11 \mathrm{Uhr}$, geben keine sichere Gmelin'sche Reaction, obgleich sie sehr dunkelgelb bis braun gefärbt aussehen, enthalten kein Blut. Die Katze ist munter, schnurrt, leckt sich, frisst.

In der Nacht vom 13-14. dunkler, schwach bluthaltiger Urin, der ebenfalls keine sichere Gmelin'sche Reaction nach dem Enteiweissen ergibt.

Den 14. um $10 \mathrm{Uhr}$ sehr stark blutfarbstoffhaltiger Urin. An den Skleren ist die Verfärbung ebenso undeutlich; Katze miant sehr viel, ist sehr schwach, frisst wenig.

Den 15. hat der Blutgehalt des Urins schon nachgelassen, an den Skleren noch immer kein sicherer Icterus, ebensowenig im Urin sichere Gmelin'sche Reaction. Katze munterer.

Am 16. hat der Blutgehalt im Harn vollkommen aufgehört, Icterus auch in den nächsten Tagen nicht nachweisbar. Das Thier erholt sich bald und zeigt nach wenigen Tagen schon absolut keine Abnormitäten mehr.

Ich begnüge mich aus der Zahl meiner Experimente nur diese 10 mitzutheilen, da ich es für vollkommen überflüssig halten muss, auch die ibrigen, die ausnahmslos genau dasselbe Resultat ergaben, zu schildern. Welches sind nun die Schlussfolgerungen, die sich aus diesen Protokollen ziehen lassen? Znerst ist es vollkommen zweifellos, dass bei Katzen mit eben derselben Sicherheit nach Application von Toluylendiamin Hämoglobinurie auftritt, wie bei Hunden der Icterus. Die Art und Weise, in welcher wir ihnen die Substanz beibringen, ist gleichgiltig, immer hat sie eine so kolossale Hämoglobinurie zur Folge, dass ich manchmal sogar den Tod der Thiere an Verblutung: durch die Harnwege befürchten musste. Diese Hämoglobinurie beherrscht durch ihre ausserordentliche Intensität die Scene derartig, dass nothgedrungen alle übrigen Erscheinungen, die gleichfalls die Wirkung des Toluylendiamin sein könnten, gänzlich in den Hintergrund gedrängt werden müssen. Betrachten wir daher vorerst diese 
eine Erscheinung etwas genauer. Vor Allem weist die mikroskopische Untersuchung nach, dass die Hämoglobinurie eine ganz reine sicher nicht ist; selten aber unzweifelhaft werden in den betreffenden Harnen mehr oder weniger veränderte Blutkörperchen aufgefunden. Es macht mich diese Thatsache sehr misstrauisch gegen die in der Literatur so häufig aufgestellten Behauptungen von reinen Hämoglobinurien. Eine stärkere, hochgradigere Hämoglobinurie als die unsrige kann ich mir kaum denken, und trotzdem sind Blutkörperchen in den einzelnen Urinportionen meistens mit Sicherheit in grösserer oder geringerer Zahl aufzufinden. Und doch ist auch wiederum der Zustand, wie er in unserem Falle vorliegt, von einer Hämaturie himmelweit verschieden. Sollten nicht die beiden Worte Hämaturie und Hämoglobinurie weniger Bezeichnungen für zwei getrennte pathologische Zastände als vielmehr für die extremsten Formen eines und desselben Zustandes sein, der die verschiedensten Abstufungen darbietet, bei welchem bald die Masse der unzerstörten Blutkörperchen über ihre Auflösungsproducte uiberwiegt, bald das umgekehrte Verhalten stattfindet? Sollten nicht Hämoglobinurie und Hämaturie Bezeichnungen für zwei, wenn ich so sagen darf, ideale pathologische Zustände sein, welche in Wirklichkeit nicht bestehen?

Auffallend ist, dass wir neben diesen seltenen Blntkörperchen niemals auch nur eine Spur von Cylindern oder Epithelien in dem Harn finden. Und dies stimmt auch sehr gut mit den mikroskopischen Befunden an der Niere. Niemals konnte ich in den Harnkanälchen Cylinder oder Reste derselben entdecken. Ebenso stimmt der Befund von Blutkörperchen im Urin mit der mikroskopischen Beobachtung an Schnittpräparaten der Niere überein. Stets konnte ich nachweisen, dass Blutkörperchen aus den Gefässen der Glomeruli ausgetreten, dass sie aber in diesen, wie es schien, fast alle zurïckgehalten waren. Wir mïssen also neben der Auflösung der rothen Blutkörperchen auch eine gewisse Alteration der Gefässwände als die unmittelbare oder mittelbare Folge der Einwirkung des Tolnylendiamin auf den Organismus der Katze annehmen. Was bedeuten nun aber die kleineren und grösseren, stark lichtbrechenden Kugeln, welche in solcher Massenhaftigkeit bei der Hämoglobinurie vorkommen? Es ist ja schon viel iuber die Natur derselben gestritten worden. Von den Einen sind sie als Fettkugelchen, von den Anderen als die Reste der untergegangenen Blutkörperehen aufgefasst worden. Ich möchte mich der Ansicht der Letzteren anschliessen und zwar aus zwei Grïnden. Einmal ist nämlich Aether vollständig einflusslos auf diese Kïgelchen, und dann findet man sie auch in so verschiedener Grösse, 
dass man alle nur denkbaren Zwischenformen leicht auffinden kann zwischen den kleinsten Körnchen und unzweifelhaft als veränderte Blutkörperchen anzusprechenden Kugeln. Ein sicherer Beweis für meine Annahme ist damit ja selbstverständlich nicht gegeben. Wie aber kommt nun diese Hämoglobinurie zu Stande? Wir sehen aus speciell daribber angestellten Experimenten ( $\mathrm{vgl}$. den ersten Theil dieser Arbeit), dass das Toluylendiamin nicht die Fähigkeit besitzt, die Blutkörperchen aufzulösen, ausserdem tritt eine Hämoglobinurie auch ein, ganz gleich, ob das Toluylendiamin per Os oder subcutan oder durch Injection in die Blutbahn selbst den Thieren beigebracht wird, und zwar fast genau immer zu derselben Zeit, zwischen 36 und 40 Stunden nach der Application. Allerdings sah ich bei subcutaner Injection in einem Falle schon nach 21 Stunden, jedoch bei Application per $O_{s}$ auch in einem Falle die Hämoglobinurie nach 28 Stunden auftreten; während wieder bei directer Injection in die Vene (vgl. Experiment No. 10) die Hämoglobinurie erst nach 36 und mehr Stunden nachweisbar war. Darf man nun annehmen, dass nach dieser verhältnissmässig langen Zeit das Toluylendiamin erst beginnen sollte seine Wirksamkeit auf den Organismus der Katze auszuüben, und zwar jetzt erst auf das Blut, mit dem es ja fast zuerst nach seiner Resorption in Berührung treten muss? Ich glaube, dass diese Annahme ganz gewiss nicht gerechtfertigt wäre, denn einmal wissen wir von den Experimenten an Hunden, dass das Toluylendiamin sehr sehnell resorbirt wird, andererseits wird auch bei der Katze der dem Medicamente anbaftende Farbstoff, wie sich dies aus meinen einzelnen Versuchsprotokollen unzweifelhaft ergibt, schon nach wenigen Stunden ausgeschieden. Das Toluylendiamin wird also auch bei der Katze rasch resorbirt und in dem Organismus weiter zersetzt. Woher rührt denn nun diese späte Hämoglobinurie. Die Zeit, in welcher sie auftritt, fällt genau mit derjenigen zusammen, in welcher sich bei den Hunden die erste vermebrte Gallensäureausscheidung im Harne zu zeigen anfängt. Es war daher natürlich mein erster Gedanke, dass auch hier ein Resorptionsicterus die erste Folge der Wirkung des Toluylendiamin wäre, und dass durch die resorbirten Gallensäuren die Hämoglobinurie veranlasst würde, ein Gedanke, der durch die Experimente anderer Autoren, z. B. v. D u s ch ${ }^{1}$ ), Leyden ${ }^{2}$ ), Hop pe u. s. w. sehr gestützt wurde, die nach Einspritzung von Gallensäuren in die Blutbahn von Thieren sehr häufig Hämo-

1) Untersuchungen und Experimente als Beitrag zur Pathogenese des Icterus. Leipzig 1854.

2) Zur Pathologie des Icterus. Berilin 1866. 
globinurie auftreten sahen. Allerdings bestanden dem gegenïber mehrere theoretische Bedenken, nämlich einmal trat in unseren Experimenten die Hämoglobinurie ausnahmslos und in solchem Grade ein, wie sie die früheren Experimentatoren mit Gallensäuren nicht beobachtet haben, und zweitens trat der Icterus, von welchem die Gallensäurewirkung hergeleitet werden sollte, in den meisten Fällen wenigstens sehr zurïck. Nun habe ich in allen den Fällen, die ich darauf hin untersuchte, niemals auch nur eine Andeutung von Gallensäuren in den einzelnen Urinen finden können, so häufig ich auch meine Untersuchungen wiederholte. Hier blieb nun allerdings noch eine offene Frage zu entscheiden, nämlich, ob sich Gallensäuren bei den Katzen auf dieselbe Weise darstellen lassen wie bei anderen Thieren, und ob dieselben auch die Pettenkofer'sche Reaction geben.

Experiment No. 11. Es wird die Galle mehrerer getödteten Katzen auf Gallensäuren verarbeitet. Dieselben wurden aus der alkoholischen Lösung mit Aether gefällt, krystallisiren nach längerem Stehen ( 6 Wochen) sehr schön aus und geben in der wässrigen' Lösung ausgezeichnet die Pettenkofer'sche Reaction, sowohl in.der sehr dunkel gefärbten Lösung als auch nach Reinigen derselben durch Thierkohle.

Es fragte sich nun, ob nicht vielleicht gewisse Stoffe im Katzenurin vorhanden wären, welche die Darstellung der Gallensäuren aus demselben verhinderten. Eine Annahme, die an und für sich wenig Wahrscheinlichkeit fïr sich hat, die ich aber durch specielle Experimente nicht in negativem oder positivem Sinne festgestellt habe. Es blieb eine weitere Möglichkeit, dass einmal äusserst geringe Quantitäten von Gallensäuren bei Katzen Hämoglobinurie za erzeugen im Stande wären, und dass andererseits diese geringen Quantitäten nicht durch den Urin ausgeschieden, sondern im Organismus verbrannt wurden. Dieser Annahme entsprechend wurden einige Experimente mit Gallensüuren, die aus Ochsengalle dargestellt worden waren, angestellt. Die durch Aether aus der alkoholischen Lösung gefällten, sehr dunkel gefärbten, nur theilweise auskrystallisirten harzartigen Massen wurden dazu verwandt, nachdem sie vollkommen auch über Schwefelsäure getrocknet waren. Ich verwandte demgemäss, wie ich wohl weiss, kein vollkommen reines Präparat von Gallensäuren. Jedoch kam es mir bei meinen Experimenten, die nur eine etwaige grössere Empfindlichkeit der Katzen gegen Gallensäuren beweisen sollten, wenig darauf an.

Experiment No. 12. Einer mittelgrossen, gesunden Katze werden den 28. VI. etwa 0,5 Gallensäuren (die Quantität ist nicht genau angegeben) um 2 Uhr Nachmittags in eine Vena jugularis injicirt. Die Katze ist bald nachher vollkommen munter, zeigt also absolut nichts Abnormes. 
Den 28. VI. Nachmittags 4 Uhr Urin klar, I.

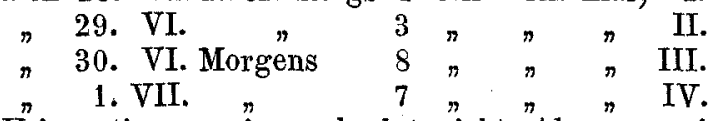

Alle 4 Urinportionen zeigen absolut nichts Abnormes, in keiner werden mit Sicherheit Gallensäuren nachgewiesen.

Experiment No. 13. Den 20. VII. Mittags $12 \frac{1}{2}$ Uhr werden einer grossen Katze von einer Lösung von 0,5:10 $3^{1 / 2}$ C.-Ctm. in eine Vena jugularis gespritzt. Gleich nach der Injection setzt die Respiration aus, der Puls wird klein, an den Pupillen und auf Kneifen der Extremitäten keine Reaction. Es wird sofort künstliche Respiration eingeleitet und nach 3-5 Minuten fängt das Thier wieder an spontan zu athmen. Der Urin bis zum 22. Mittags zeigt nichts Abnormes.

Am 22. zwischen 121/2-11/4 Uhr werden der Katze wiederum von derselben Lösung in die eine Vena jugularis injicirt. Schon nach $11 / 4-11 / 2$ C.-Ctm. Aussetzen der Respiration, verlangsamte Herzaction und Schwäche derselben. Es wird sofort künstliche Respiration eingeleitet und nach 3-5 Minuten tritt wieder normale Athmung ein. Es werden ihr nun im Laufe von 35-40 Minuten im Ganzen 10 C.-Ctm. obiger Lösung, d. h. 0,5 Gallensäuren injicirt, ohne dass sich die Anfälle in ähnlicher Intensität wiederholen. Dagegen tritt nach jeder erneuten Injection langsamere Athmung und Herzaction ein. Um 4 Uhr scheidet die Katze einen dunkelrothen Urin aus, der bluthaltig aussieht. Beim Kochen und Ansäuern fällt ein schmutzigbrauner, flockiger Niederschlag aus, doch ist der Hämoglobingehalt nicht bedeutend. Spectroskopisch sind die Hämoglobinstreifen deutlich sichtbar. Mikroskopisch einige zweifelhafte $\mathrm{Cy}$ linder. Gmelin'sche Reaction gelingt nicht, dagegen kann ziemlich reichlicher Gehalt an Urobilin nach Zusatz von Ammoniak and Chlorzink spectroskopisch und durch Fluorescenz nachgewiesen werden.

Den 22. um 8 Uhr normaler Urin.

Den 23. um 6 Uhr Abends normaler Urin.

Die Katze ist ziemlich munter, wenn auch nicht ganz so wie vorher.

Experiment No, 14. Den 26. 1 Uhr Mittags werden derselben Katze 0,5 Gallensäuren hypodermatisch beigebracht. Um 51/2 Uhr wird ein klarer, gelbgrünlicher, stark fluorescirender Urin entleert, der eine schwache Gmelin'sche Reaction ergibt. Den 27. um 7 Uhr wird ein dunkler, klarer, eiweiss- und hämoglobinfreier Urin entleert, der exquisite Gmelin'sche Reaction gibt.

Den 27. um 2 Uhr

28. 6 ähnliche Urine ohne Albumen und Hämoglobin.

Methylviolett ergab nirgends einen Farbenumschlag sondern nur mehr weniger erhebliche Farbenveränderung.

Experiment No. 15. Einer kräftigen Katze, die vor Kurzem geworfen hat and die $2640 \mathrm{Grm}$. wiegt, werden den 30 . Mittags 1 Uhr 0,8 Gallensäuren hypodermatisch beigebracht.

Abends 6 Uhr ein normal aussehender Urin, Gmelin'sche Reaction gelingt nicht, Methylviolett gibt keine Veränderung.

Den 31. 1 Uhr Mittags ein etwas icterisch aussehender Urin ohne 
Albumen, in welchem die Gmelin'sche Reaction kein Resultat ergibt. Mit Methylviolett Farbenumschlag.

Den 31. Abends 8 Uhr Urin ohne Albumen, ergibt undeutliche Gmelin'sche Reaction, mit Methylviolett Farbenumschlag. Die Katze ist matt, frisst wenig, zeigt aber sonst nichts Auffallendes.

Den 1. XI. Normaler Urin, der keine Gmelin'sche Reaction ergibt.

Die Beobachtungen werden bis zum 4 . fortgesetzt und dann, da der Urin niemals etwas Abnormes zeigt, ausgesetzt.

Experiment No. 16. Einem kleinen Hunde, der 3020 Grm. wiegt, werden 0,9 Gallensäuren hypodermatisch den 5. XI. beigebracht.

Den 6. XI. Mittags 11/4 Uhr ein gelblichgrüner, stark alkaliseher, trüber Urin, der Spuren von Albumen und Gallenfarbstoff enthält. Methylviolett ergibt an ihm erhebliche Farbenveränderung.

Den 7. normaler Urin ohne Albumen und Gallenfarbstoff.

Bis zum 10. tritt keine Abnormität im Urin auf, und wird dann der Versuch abgebrochen.

An den Stellen der Injection der Gallensäuren treten meistens Abscesse oder wenigstens sehr erhebliche Indurationen auf.

Diese letzten Experimente, bei denen Katzen Gallensäuren subcutan und durch directe Injection in die Blutbahn in so bedeutenden Quantitäten beigebracht waren, dass sie sogar das Leben der Thiere gefährdeten, sprechen sehr wenig dafür, dass unsere Hämoglobinurie von Gallensäuren bedingt worden sei, denn nach Injection derselben trat eine so seltene und so geringe Hämoglobinurie ein, dass man von einer besonderen Empfindlichkeit der Katzen gegen Gallensäuren abșolut nicht sprechen kann.

Die nach Application von Toluylendiamin bei Katzen auftretende Hämoglobinurie bleibt demnach vorläufig vollkommen dunkel. Wie verhält es sich nun aber mit dem Icterus, wird dieser ebenfalls durch das Toluylendiamin bei den Katzen hervorgerufen und ist er, wenn wirklich vorhanden, nicht vielmehr die Folge der Hämoglobinurie, d. h. ein sogenannter hämatogener? Es ist wohl unzweifelhaft, dass der Icterus bei den Katzen durch die kolossale Hämoglobinurie vollkommen in den Hintergrund gedrängt wird, sich leicht der Beobachtung und Sicherstellung entzieht und manchmal nur bei speciell darauf gerichteter Aufmerksamkeit erkannt werden kann. Sehr viel stärker tritt der Icterus im Allgemeinen bei den Sectionen der Thiere hervor, während er bei Lebzeiten nur undeutlich war, und habe ich wenigstens bei meinen Experimenten den Eindruck gewonnen, als ob bei Katzen ein Icterus der Skleren in hohem Grade nicht aufzutreten pflegt. Besonders die Experimente 7, 8, 9, die speciell darauf hin angestellt waren, beweisen unweifelhaft, dass nach Application von Toluylendiamin per Os und subcutan nicht nur Gallen- 
farbstoff im Harne, sondern auch richtiger Gewebsicterus auftritt. Der Gallenfarbstoff im Harn konnte nach dem Enteiweissen der Urinesehr oft mit Sicherheit nachgewiesen werden. Wie ist nun aber das Verhältniss dieses Icterus zur Hämoglobinurie? Hier kann ich nun mit Bestimmtheit behaupten, und hauptsächlich die Experimente 7, 8,9 beweisen auch dieses, dass der Icterus nicht selten der Hämoglobinurie vorausgeht und während des Bestehens der Hämoglobinurie nicht etwa zu- sondern unzweifelhaft abnimmt. Der Icterus beginnt, wie bei den Hunden, nach 24-48 Stunden und endet entsprechend seiner Intensität, die ja bei den Katzen ausserordentlich geringer ist, in kürzerer oder längerer Zeit.

Ich kann demnach die Resultate meiner Experimente dahin resumiren, dass als Wirkung des Toluylendiamin auf den Organismus der Katze zuerst ein mässiger Icterus und dann eine der Höhe der Gabe entsprechende, mehr minder hochgradige Hämoglobinurie auftritt, dass die Beziehungen des Icterus zu der Hämoglobinurie noch dunkel sind, dass jedoch der Icterus unzweifelhaft nicht die Folge der Hämoglobinurie ist.

Experimente an Kaninchen.

Experiment No. 1. Einem Kaninchen werden 0,1 Toluylendiamin in eine Vena jugularis gespritzt, Es ist danach ganz munter, frisst wie vorher. Der Harn am nächsten Tage ist stark dunkel gefärbt, der darauf folgende ist sehr bedeutend heller. Mit beiden gelingt die Gallenfarbstoffreaction nicht (Gmelin'sche).

Experiment No. 2. Einem Kaninchen werden am 28. Nachmittags 4 Uhr 0,2 Toluylendiamin in eine Vena jugularis injicirt. Es ist danach ganz munter. Den 29. Abends ist noch kein Harn gelassen. Der dann abgedrückte ist trübe, sehr dunkel, gibt ebensowenig die Gmelin'sche Reaction, wie der am 30 . entleerte, etwas hellere Urin. Beide enthalten kein Blut.

Experiment No. 3. Den 2. I. werden einem gesunden Kaninchen 0,5 Toluylendiamin per Os beigebracht. Am nächsten Morgen wird eine geringe Quantität eines gelben Urins abgedrückt, der nach kurzer Zeit gelatineartig gerinnt, Gallenfarbstoffreaction gelingt nicht, der Urin enthält kein Albumen, kein Sediment, nur etwas Schleim. Den 4., 5., 7., 9., 11., 13., 15., 17., 19., 21., 23., 26. erhält das Thier je 0,5 Toluylendiamin per 0s. Der entleerte Urin sieht immer stark gelb aus, doch ergibt die Gmelin'sche Reaction niemals ein deutliches Resultat, dagegen ergibt Methylviolett stets Farbenumschlag. Auch nach Ausfällen der Urine mit Kalk, Ansäuern und Schütteln mit Chloroform können keine Gallenfarbstoffkrystalle erhalten werden, sondern es bleibt, mit Fett und schwarzen Schmieren untermischt, eine intensiv gelbgrün gefärbte Masse zurück. Die mikroskopische Untersuchung ergibt niemals erhebliche Ab- 
normitäten, meistens neben detritusartigen Massen die bekannten cylinderartigen Bänder, die ja auch in normalem Kaninchenurine häufig zu finden sind. Dabei sind die Urine, obgleich sie immer abgedrückt werden, sehr trübe, reagiren sauer, enthalten eiweissartige Stoffe. An den Skleren des Thieres, das sehr abmagert, ist nie etwas Abnormes zu entdecken. Obgleich das Thier ziemlich gut frisst, nehmen doch die abgesonderten Urinquantitäten sehr erheblich ab.

Den 28. I. ist das Thier sehr elend, frisst nichts, vermag sich kaum noch auf den Beinen zu halten, der Herzschlag ist sehr sehwach, kaum fühlbar. Die Schleimhänte sind ausserordentlich blass.

Am 29. ist das Thier todt.

Section: Sehr starke Anämie, Herz schlaff, fast ganz blutleer. Das Blut ist sehr dunkel, zeigt mikroskopisch nichts Abnormes. Gallenblase ist stark gefüllt, Icterus der Organe ist nicht mit Sicherheit nachzuweisen. Mikroskopische Untersuchung ergibt nichts Besonderes.

Experiment No. 4. Den 23. III. werden einem gesunden Kaninchen, dessen Harn keine besonderen Abnormitäten zeigt, 0,5 Toluylendiamin per Os beigebracht. Der Harn zeigt danach wenig Abnormes.

Den 26. und 28. erhält es dieselbe Dosis.

Den 28. wird ein dunkler, brätunlicher Urin entleert, der eiweissartige Massen enthält, kein Hämoglobin, keinen nachweisbaren Gallenfarbstoff. Mikroskopisch enthält er mässig reichliche amorphe Massen.

Den 29. ein ähnlicher Urin; es erhält wieder 0,5 Toluylendiamin.

Den 30. Abends wird ein ausserordentlich stark sedimentirter, griesartiger Urin entleert. Das Sediment besteht fast nur aus amorphen Massen, die stark zusammengeballt sind, daneben auch Krystalle von der Form der Hippursäure. Gmelin'sche Reaction ergibt kein Resultat.

Bis zum 3. IV. erhält das Kaninchen täglich 0,5 Toluylendiamin, von da ab nicht mehr. Der Harn ist immer stark sedimentirt mit denselben Massen, ohne 'Albumen, ohne nachweisbaren Gallenfarbstoff (auch nicht durch Huppert'sche Reaction).

Am 10. V. werden dem Kaninchen, dessen Harn wieder vollkommen normal geworden ist, 0,3 Toluylendiamin hypodermatisch beigebracht.

Den 11. ist der Urin wieder stark sedimentirt, gibt keine Gmelin'sche Reaction, mit Methylviolett Farbenumschlag.

Den 13. ist der Urin wieder normal. Am Thier selbst ist kein Ieterus wahrnehmbar.

Den 15. IV. Abends $6 \mathrm{Uhr}$ werden dem Thiere, welches sehr abgemagert ist und auffallend wenig Urin lässt, 1,0 Toluylendiamin subcutan beigebracht.

Den 16. Morgens 10 Uhr liegt das Thier im Sterben. Es wird durch Entbluten aus der Carotis getödtet und 25 C.-Ctm Blut auf Gallensäuren verarbeitet.

Section: Eine geringe gelblichgrüne Verfärbnng der Haut. An den Körperorganen kein sicherer Icterus, Harnblase leer, kein Hervortreten der Lymphgefässe. Das Fettgewebe fast vollkommen geschwunden. Gallenblase stark gefüllt, Galle normal, Ductus choledochus vollkommen frei. Die Untersuchung des Blutes auf Gallensäuren ergibt negatives Resultat. 
Experiment No. 5. Der Urin eines mittelgrossen gesunden Kaninchens $(271 / 2$ C.-Ctm.) wird auf Gallensäuren untersucht mit negativem Erfolge. Der Urin ist wie so häufig bei Kaninchen trübe, enthält eiweissartige Massen, Gmelin'sche Reaction resultatlos.

Den 9. Abends erhält es 0,5 Toluylendiamin per Os, ebenso den 10. und 11. Die danach entleerten Urine sind sehr stark gelb, geben keine Gmelin'sehe Reaction, mit Methylviolett Farbenumschlag. Huppert'sche Reaction gelingt auch nicht.

Den 12. Abends wiederum 0,5 Toluylendiamin.

Den 13. Morgens wird ein sehr dunkler, des Abends ein heller Urin entleert, spec. Gew. 1059 , sauer, 30 C.-Ctm. werden auf Gallensäuren verarbeitet mit negativem Erfolge. Gmelin'sche Reaction resultatlos.

Den 13. Abends wiederum 0,5 Toluylendiamin.

Den 14. Morgens sehr stark bernsteingelber Urin, der die Gmelin'sche Reaction nicht gibt. 30 C.-Ctm. werden mit negativem Erfolge auf Gallensäuren verarbeitet. Die Lösung wird nach Zusatz von Zucker und $\mathrm{H}_{2} \mathrm{SO}_{4}$ und Erwärmen zwar röthlich aber mehr rothbraun, nicht mit der hochrothen Farbe der unzweifelhaften Pettenkofer'schen Reaction.

Den 14. wiederum 0,5, ebenso den 15. und 16.

Keiner der danach entleerten. Urine gibt die Gmelin'sche Reaction oder enthält Gallensäuren.

Nachdem das Thier bis zum 27. fast täglich 0,5 Toluylendiamin erhalten hatte, und die Urine stets mit negativem Erfolge auf Gallenfarbstoff und Gallensäuren untersucht worden waren, stirbt das Thier den 27. unter zunehmender Abmagerung und Entkräftung.

Section: Geringe icterische Verfärbung der Haut, starke Anämie sämmtlicher Organe, Leber fast schwarz aussehend, ausserordentlich blutreich. Kein Gewebsicterus. Gallenblase prall gefüllt, im Darm ausserordentlich stark gallig gefärbte Massen.

Experiment No. 6. Der Urin eines anscheinend gesunden kräftigen Kaninchens wird mit negativem Erfolge zu wiederholten Malen auf Gallensäuren untersucht.

Den 13. VII. Abends erbält es 0,5 Toluylendiamin.

Den 14. ist der Urin dunkelbraun, icterisch aussehend, dick aber klar, ohne Albumen. Gmelin'sche Reaction resultatlos, mit. Methylviolett Farbenumschlag. 20 C.-Ctm. werden mit negativem Erfolge auf Gallensäuren untersucht.

Den 15. VII. Urin braun, sehr trübe, sieht bluthaltig ans. Beim Kochen und Ansäuern fällt ein reichliches schmutzigbraunes Coagulum aus. Mikroskopiseh sehr viele theils zersetzte Blutkörperchen. Im Filtrat keine Blutkörperchen. 20 C.-Ctm. werden auf Gallensäuren untersucht und geben deutliche Gallensäurereaction.

Den 15. Abends erhält das Kaninchen 0,5 Toluylendiamin.

Den 16. Morgens ist es todt.

Section: Starke Anämie, eitrige Pleuritis, einige verkäste Lymphdrisen. Darminhalt ausserordentlich gallenfarbstoffreich. Sonst die alten Verhältnisse. 
Experiment No. 7. Ein gesundes Kaninchen wird längere Zeit beobachtet, sein Urin häufig resultatlos auf Gallensäuren untersucht. Gmelin'sche Reaction gelingt nie. Es erhält in der Zeit vom 7. bis 17. X. täglich $0,5-1,0$ Toluylendiamin per 0 s. Die Urine werden sämmtlich auf Gallenfarbstoff und Gallensäuren untersucht, stets vergeblich. Methylviolett ergibt mit den meisten einen vollkommenen Farbenumschlag.

Vom $17-26$. erhält es täglich $0,75-1,0$ Toluylendiamin per 0 s, danach wird häufig ein vollkommen grüner, fast identisch mit der grünen Kaninchengalle aussehender Urin entleert, der jedoch niemals die Gmelin'sche Reaction ergibt. Den 26. ist das Thier todt.

Die Section ergibt deutliche gelbgrünliche Verfärbung der Haut, des Felles, nicht aber der inneren Organe und der Skleren. Die Gallenblase ist prall gefüllt, die Leber sehr blut- und gallenreich.

Experiment No. 8. Kräftiges graues Kaninchen.

Urin am 3. I. trübe, gelblich, stark alkalisch, enthält eiweissartige Stoffe, Gmelin'sche Reaction resultatlos, mit Methylviolett keine deutliche Farbenveränderung.

Den 5. I. Urin tribe, gelblich, enthält Eiweissstoffe, Gmelin'sche' Reaction resultatlos.

Den 8. I. dasselbe Verhalten des Urins, Gmelin'sche Reaction gelingt nicht.

Den 11. I. Urin gelblich, trïbe, schwach saner, enthält geringe Mengen eiweissartiger Stoffe. Gmelin'sche Reaction gibt nur gelbbraunen Ring, mit Methylviolett geringe Farbenveränderung. cutan.

Den 27. I. Abends erhält das Kaninchen 0,31 Toluylendiamin sub-

Urin am 28. dunkelbraun, icterisch, klar, Gmelin'sche Reaction resultatlos, mit Methylviolett vollkommener Farbenumschlag. Beim Kochen nnd Ansäuern fällt kein Albumen aụs.

Den 28. Abends ist der Urin weniger icterisch, hat einen dunkeln Bodensatz, enthält kein sanguis, Reaction schwach sauer, Methylviolett gibt nur Farbenveränderung, Gmelin'sche Reaction resultatlos.

Den 29. sieht der Urin vollkommen klar, hell, normal aus, mit Methylviolett keine Farbenveränderung mehr, Gmelin'sche Reaction resultatlos.

Den 30. I. Dasselbe Verhalten.

Den 31. Abends erhält das Thier wiederum 0,31 Toluylendiamin subcutan. Der Urin zeigt danach dasselbe Verhalten wie nach der vorigen Injection, gibt in den ersten Tagen mit Methylviolett Farbenumschlag, Farbenveränderung, während Gmelin'sche Reaction nie gelingt.

Dén 2. II. erhält das Thier 0,51 Toluylendiamin subcutan.

Den 3. II. Morgens ist der Urin kolossal dunkelgelb, gibt mit $\mathrm{Me-}$ thylviolett selbst bei starker Verdünnung Farbenumschlag, Reaction sauer, Gmelin'sche Reaction stets resultatlos.

Abends dasselbe Verhalten.

In den nächsten Tagen wird der Urin wieder langsam vollkommen normal. Nach einiger Zeit stirbt das Thier unter grosser Abmagerung. Section findet nicht statt. 
Experiment No. 9. Ein Kaninchen, welches schon seit längerer Zeit hin und wieder kleinere Dosen von Toluylendiamin bald per Os, bald subcutan erhalten hat und dessen Urin danach stets die schon bekannten Veränderungen gezeigt hat, erhält am 29. IV. Abends 0,81 Toluylendiamin.

Den 1. V. Morgens dunkelbrauner Urin, sauer, der starken Farbenumschlag gibt.

Den 2. Morgens wenig Urin, heller, gibt mässig starke Farbenveränderung.

Den 4. ist das Thier todt.

Section: Starke Grünfärbung der Haut und mässige Gelbfärbung der inneren Organe, im Darm ausserordentlich stark gallig gefärbte Massen. Gallenblase prall gefuillt. Leber ausserordentlich bIutreich. Mikroskopisch nichts Abnormes. In keiner der Urinportionen werden Gallensäuren gefunden.

Experimennt No. 10. Ein gesundes kräftiges Kaninchen hat mehrere Male Toluylendiamin erhalten. Eine von den danach entleerten Urinmengen, die ausserordentlich dunkelgelb, icterisch aussieht, wird mit Kalk gefällt, schwach mit verdünnter $\mathrm{HCl}$ angesäuert, mit Chloroform geschüttelt. Das Chloroform wird nach ganz kurzer Zeit vollkommen grün. Nach dem Abdampfen gelingt es nicht, ordentliche Krystalle zu erhalten, sondern man bekommt nur eine grünlichbraune schmierige Masse, in der keine sicheren, schönen Krystalle aufzufinden sind.

Experiment No. 11. Ein kräftiges braunes Kaninchen bekommt am 15., 16., 17. VI. 0,1 Toluylendiamin, den 19. und 20. 0,2, den 21., 22. und 23. 0,3, den 24. und 25. 0,5. Danach werden Urinportionen entleert, die sehr dunkelbraun, einigemal auch exquisit griun gefärbt sind, in denen Gmelin'sche Reaction niemals gelingt. Den 26. wird ein kolossal dunkelbrauner, fast schwarzer Urin entleert, der bei auffallendem Lichte grïn aussieht. Auf Zusatz von Chlorealeium, Kalkmileh und Waschen des Niederschlages mit kohlensaurem Ammoniak wird ein dunkler Farbstoff gefällt, während das Filtrat sehr schön grün gefärbt ist. An der Luft wird die Farbe des Filtrats rothbraun, durch Schiitteln mit Luft wieder grün, durch Salzsäure roth und durch $\mathrm{NH}_{3}$ wunderschön gesättigt grïn, selbst in der grössten Verdünnung. Da es nicht gelang, selbst nach so hohen Gaben von Toluylendiamin bei dem Thiere nachweisbaren Gewebsicterus hervorzurufen, so wurde von weiteren Gaben Abstand genommen. Zwei Tage, d. h. den 28. wird von dem şehr heruntergekommenen, besonders sehr anämischen Thiere ein sebr exquisit bluthaltiger Urin entleert, der mikroskopisch keine nachweisbaren. Blutkörperchen enthält, wogegen spectroskopisch sehr dentliche Absorptionsstreifen des Hämoglobin aufzufinden sind. Keine Cylinder. In den nächsten Tagen ist der Urin wieder bernsteingelb, ohne Blut und Albumen. Etwa 14 Tage seitdem es kein Toluylendiamin mehr erhalten hat, stirbt das sehr abgemagerte Thier. Section ergibt hochgradige Anämie, in Pleurahöhle, Pericardial - und Peritonealhöhle blutig seröse, vollkommen klare Flüssigkeit. Die serösen Häute bieten keine Spur einer Entzündung. Harnblase leer, Darm mit sehr intensiv gelb gefärbten Massen gefüllt. Linke Lunge hart, indurirt, fast ganz luftleer; sonst nichts Abnormes. 
Nicht allein bei dieser Gelegenheit hatte ich ein derartiges merkwürdiges Grünwerden des Kaninchenurins nach vorhergegangener Application von Toluylendiamin gesehen. Mehrfach war von den Thieren ein Urin gelassen worden, der eine grüne Farbe, ähnlich der Galle der Thiere, bald nach seiner Entleerung annahm. Worin dies merkwürdige Verhalten seinen Grund hat, habe ich leider nicht eruiren können. Dagegen ist es ausserordentlich leicht, in einer der, in Folge von Gaben des Toluylendiamin dunkelgelb gefärbten Urinportion folgende Beobachtungen zu machen.

Versetzt man einen derartigen Kaninchenurin, den man auf Gallensäuren untersuchen will, nach der Angabe von Hoppe-Seyler mit ein paar Tropfen Ammoniak und fällt ihn dann mit Bleiessig aus, so bemerkt man, wenn man das Glasgefäss eine Weile an der Luft stehen lässt, schon nach kurzer Zeit, etwa 10 Minuten, deutlich, wie die obersten Schichten der Flüssigkeit, d. h. diejenigen, welche mit Licht und Luft am meisten in Beriihrung kommen, anfangen grün gefärbt zu werden, dagegen nehmen die tieferen Schichten eine mehr braune, braungelbe Farbe an. Rührt man nun den ganzen Niederschlag um, so verschwindet die grüne Farbe, stellt sich jedoch nach kurzer Zeit wieder ein und zwar zuerst wieder an der Oberfläche. Die Bleiausfällung ist meistens zum Zustandekommen dieser Grünfärbung, die immer tiefere Schichten erfasst, sodass schliesslich nach kürzerer oder längerer Zeit, nachdem der Bleiniederschlag sich vollkommen abgesetzt hat, die ganze klare Flïssigkeit über demselben hell-dunkelgrün, ja sogar blaugrün gefärbt ist, nicht nothwendig, scheint sie dagegen zu unterstïtzen.

Ammoniak allein macht selbst bei massenhaftem Zusatz die Flüssigkeit und den Niederschlag nicht mit einem Schlage griun, sondern immer findet der oben geschilderte Vorgang statt, d. h. die obersten Schichten werden zuerst grün, und dann zieht sich der Process immer tiefer und tiefer herab, sodass, wenn man lange genug wartet, auch die obersten Schichten des Niederschlages diese grïne Farbe anzunehmen beginnen. Es lässt sich also vermuthen, dass hier ein Oxydationsprocess stattfindet. Wenn man eine derartig: grün gewordene Flüssigkeit und den abgesetzten noch nicht verfärbten Niederschlag durcheinander rührt und dann filtrirt, so wird das Filtrat oft, statt grün zu bleiben, braun und braungelb. Setzt man dann zu dem Filtrat etwas $\mathrm{NH}_{3}$, so wird es sofort und zwar dann die ganze Flüssigkeit grün, zugleich fällt etwas überschüssiges Blei aus. Wenn man den gleichfalls grünblau gewordenen Bleiniederschlag in Fortsetzung der Untersuchung auf Gallensäuren auf dem 
Filter sammelt, in Alkohol aber stark kocht, so verschwindet die grïne Farbe, die kochende, alkoholische Flüssigkeit nimmt einen reingelben resp. gelbbraunen Farbenton an. Filtrirt man nun, so wird das Filtrat, sowie es in die kalte Porzellanschale hineintropft, blau resp. grïn. Giesst man nun zu dieser grünen alkoholischen Flüssigkeit Natriumhydrat, so wird sie röthlichgelb. Auch verhindern Kali und Natronlauge, in genügender Menge zugesetzt, das Grünwerden des mit Blei ausgefällten und mit $\mathrm{NH}_{3}$ versetzten Urins, oder machen die grüne Farbe verschwinden. Setzt man zu dem grüngefärbten Alkoholfiltrat etwas $\mathrm{NH}_{3}$, so tritt die grune Farbe in der oft etwas gelbgrünen Fliissigkeit schöner hervor. Setzt man zu dem grüngewordenen Urine Kali und Natronlange, so schlägt die Farbe in rothgelb um. Salpetersäure verwandelt das Grün in Burgunderroth, $\mathrm{NH}_{3}$ macht wieder die grüne Farbe hervortreten. Wie Salpetersäure verhalten sich auch Essigsäure, $\mathrm{H}_{2} \mathrm{SO}_{4}, \mathrm{HCl}$. Ueberall aber lässt $\mathrm{NH}_{3}$ die grüne Farbe wieder auftreten. Aether nimmt den grünen Farbstoff in mässigem Grade an, nicht dagegen den durch Säuren erhaltenen rothen. Chloroform nimmt den grïnen resp. blauen Farbstoff recht gut auf, nicht dagegen den rothen, der durch Chloroformeinfluss etwas heller gemacht wird.

Woher rührt nun dieser grüne Farbstoff? Ich habe mich lange mit dem Gedanken getragen, dass derselbe Biliverdin sei, welcher durch unbekannte Einfliusse des Kaninchenharns aus dem nicht nachweisbaren aber dennoch möglicherweise in demselben enthaltenen Bilirubin entstände. Doch musste ich schliesslich diese Idee aufgeben, als ich fand, dass die Reactionen, welche Staedeler ${ }^{1}$ ) allerdings für Biliverdin der Menschengalle angibt, mit meinem Farbstoffe absolut nicht übereinstimmen. Unser Farbstoff löst sich absolut nicht in Alkohol, Salzsäure ruft keinen Niederschlag, sondern Farbenumschlag von grün in burgunderroth hervor a. s. w. Demnach möchte ich nunmehr diesen Farbstoff fïr eine Umwandlung des Toluylendiamin selbst oder des mit demselben verbundenen braunen Farbstoffes erklären. Der Umstand, dass bei den Hunden und Katzen eine derartige Umwandlung in dem Organismus der Thiere nicht statt hatte, wird ja schon leicht durch den Unterschied zwischen Herbivoren und Carnivoren erklärt, der ja in vielen anderen experimentellen Untersuchungen so häufig constatirt worden ist.

Jedenfalls wollte ich es nicht unterlassen den Versuch zu machen, ob es nicht gelänge, durch Entfernung des Farbstoffes des Toluy-

1) Ueber die Farbstoffe der Galle. Moleschott's Untersuchungen. IX. 395. 
lendiamins diese Grünfärbung des Urins zu vermeiden. Hier stellte sich aber das schon früher geschilderte Hịderniss in den Weg, indem es selbst durch dreimaliges Umkrystallisiren nur gelang, den Farbstoff theilweise za entfernen.

Experiment No. 12. Ein Kaninchen, das allerdings nicht vollkommen normal zu sein scheint, indem sein Urin mehrmals, wenn auch geringe Mengen von Blut enthiel, erhält am 25. II. um 11 Uhr Vormittags 0,41 des gereinigten Toluylendiamin, dessen Lösung wenig aber doch entschieden bräunlich gefärbt ist.

Den 25. um 2 Uhr brauner Urin mit starkem Sediment aus Tripelphosphaten, stark alkalisch. Gmelin'sche Reaction resultatlos, mit Methylviolett Farbenumschlag.

Um 6 Uhr ein Urin mit dem gleichen Verhalten. Gmelin'sche Reaction gibt nur einen braunen Ring, mit Methylviolett Farbenumschlag.

In der Nacht rom 25-26. ziemlich klarer, nicht sedimentirter Urin ohne Albumen, mässig alkalisch, braun. Gmelin'sche Reaction gibt nur braunen Ring, mit Methylviolett Farbenumschlag.

Den 26. um 10 Uhr klarer Urin, hell, fast normal, Gmelin'sche Reaction gibt schwach violetten Ring. Das Thier erhält um 10 Uhr 0,51 desselben Toluylendiamin per Os. An den Skleren ist eine schwache braungelbe Verfärbung nachweisbar.

Um 2 Uhr brauner Urin, klar, Gmelin'sche Reaction resultatlos.

Um $8 \mathrm{Uhr}$ ansserordentlich dunkelbrauner Urin, der ebenfalls keine Gmelin'sche Reaction gibt.

In der Nacht vom 26-27. ein Urin gleich dem vorigen. An den Skleren nimmt die braungelbe Verfärbung noch zu, jedoch ist sie nicht gleich der Farbe, die beim Icterus der Menschen und Hunde auftritt.

Den 27. Morgens grünlicher Urin, trübe, stark alkalisch, gibt keine Gmelin'sche Reaction. Ueber Nacht verschwindet die grünliche Farbe, sie ist in eine braune uibergegangen.

Den 28. ein wenig gelblicher Urin; um 5 Uhr erhält das Thier 0,51 des ungereinigten Toluylendiamin per Os.

1. III. Die schmutzigbrangelbe Verfärbung an den Skleren hat noch zugenommen. Um $8 \mathrm{Uhr}$ wird ein wundersehön goldgelber Urin entleert, der exquisit das Aussehen frischer Galle hat. Gmelin'sche Reaction resultatlos.

Um $10 \mathrm{Uhr}$ ein gleicher Urin. Um $12 \frac{1}{2} \mathrm{Uhr}$ bekommt das Thier 0,51 Toluylendiamin (ungereinigt) per Os. Um 4 Uhr brauner Urin, der keine Gmelin'sche Reaction ergibt.

In der Nacht vom 1-2. hellerer Urin. Morgens wird das Thier todt gefunden.

Section: Gelbliche Verfärbung der Haut. Leber sehr gallen- und bluthaltig, Gallenblase prall gefüllt. Im Pericard gelblichgrïn gefärbte, klare Flüssigkeit. Lungen sehr gross, hart, stark ödematös. In der Blase gelber Urin, der keine Gmelin'sche Reaction ergibt.

Experiment No. 13. Den 3. III. erhält ein lange beobachtetes Kaninchen, das keine Abnormitäten darbietet, um 11/1/2 Uhr 0,51 gereinigten 
Toluylendiamin. Um 11/2 Uhr stark durkler, brauner Urin, der keine Gmelin'sche Reaction, mit Methylviolett Farbenumschlag gibt. Auf Zusatz weniger Tropfen Ammoniak wird er schnell dunkelgrün, bei Ausfällen mit Bleiessig wird ein schmutzig grüner Niederschlag gebildet. An den Skleren des Thieres nichts Abnormes. Den 4. III. ähnlicher Urin.

Um 11 Uhr 0,51 des gereinigten Toluylendiamin.

Um 3 Uhr brauner Urin, schwach sauer, auf Zusatz von $\mathrm{NH}_{3}$ wird er stark grün. Bleiessig fällt einen grünlichen Niederschlag, der nach längerer Zeit sehr schön grün wird.

Ein ähnliches Verhalten des Urins kann nach jeder weiteren Gabe von Toluylendiamin beobachtet werden. Die Grünfärbung des Urins ist durchaus nicht schwächer als nach Application von ungereinigtem Toluylendiamin. Es scheint demnach dieser Farbstoff durch eine Veränderung der Substanz selbst im Kaninchenorganismus bedingt zu werden.

Der Erfolg einer genügenden Quantität Toluylendiamin -- und die Kaninchen vertragen ausserordentlich grosse und häufige Dosen dieser Substanz - ist demnach wahrscheinlich gleichfalls ein Icterus, wenn ich auch zugeben muss, dass derselbe, da uns die gewöhnlichen Reactionen auf Gallenfarbstoff hier gänzlich im Stiche lassen, nicht vollkommen sicher gestellt ist. Die manchmal hervortretende Verfärbung der Skleren und das noch sehr viel häufigere icterische Aussehen der Haut und selbst der inneren Organe, die ich mir kaum anders erklären könnte, lassen mich trotzdem die Behauptung, dass wir auch hier wirklichen Icterus vor uns haben, aufrecht erhalten. Gallensäuren konnten nur in einem Falle unzweifelhaft von mir nachgewiesen werden, jedoch wird wohl in den meisten Fällen die Pettenkofer'sche Reaction durch den nicht aus dem Urin zu entfernenden Farbstoff sehr erheblich gestört, so dass sie trotzdem in den uibrigen Fällen sehr wohl im Urin vorhanden, nur nicht nachweisbar sein konnten. - Dieselbe Substanz bewirkt demnach bei Hunden reinen Icterus, bei Katzen Hämoglobinurie und daneben Icterus, bei Kaninchen wahrscheinlich gleichfalls Icterus.

Wenn nun dieser Ieterus, was ganz zweifellos ist, ein Resorptionsicterus bei den Hunden ist, kann dann der Icterus bei den Katzen ein hämatogener sein, und wie sind die Experimente Nr. 11 bei den Hunden und No. 11 bei den Kaninchen zu erklären, bei denen gleichfalls eine sehr erhebliche Hämoglobinurie das auffallendste Symptom nach der Application von Toluylendiamin war, und die so ganz vereinzelt und abweichend von allen ïbrigen Experimenten in den betreffenden Thierklassen dastehen? Ich glaube die erste Frage müssen wir auf das entschiedenste verneinen. Wir haben absolut keinen 
Anhaltspunkt in der ganzen experimentellen Pathologie für eine Annahme, dass dieselbe Substanz bei Hunden hepatogenen und bei Katzen hämatogenen Icterus hervorrufen könne, eine Substanz, von der noch dazu nachgewiesen ist, dass sie wenigstens ausserhalb des Organismus die rothen Blutkörperchen nicht alterirt. Wohl aber. beweist diese Thatsache, was durch die beiden einzelnen oben angeführten Experimente noch mehr bestätigt wird, die so häufige Coincidenz von Icterus und Hämoglobinurie aus allerdings noch unaufgeklärten Ursachen, eine Coincidenz, die in der Pathologie des Menschen so oft schon beobachtet ist. Ich erinnere nur an den Fall von Immer$\operatorname{man} \mathbf{n}^{1}$ ), an den Fall von Heabner ${ }^{2}$ ), an die Fälle von Vergiftung mit Arsenwasserstoff ${ }^{3}$, an die Vergiftungen mit Kali chloricum ${ }^{4}$ ), die Fälle von periodischer Hämoglobinurie ${ }^{\tilde{}}$ ), Fälle, die so häufig als Beispiele für hämatogenen Icterus angeführt sind und die das gemeinsame haben, dass im Laufe einer Hämoglobinurie eine mehr weniger starke Gelbfärbung des Icterus resp. der Haut auftrat. Ich versage es mir gerne, mit einer eingehenderen Kritik an diese Fälle heranzutreten, jedenfalls ist in allen von ihnen die Natur des Icterus als hämatogener nicht im entferntesten bewiesen, anch haben mehrere der Autoren, z. B. Heubner und Küssner und vor allem Lichtheim durchaus nicht daran gedacht eine derartige Behauptung aufzustellen. Sie beweisen eben nichts mehr und nichts weniger, als däss Icterus und Hämoglobinurie zu gleicher Zeit bei gewissen Erkrankungen vorkommen, dass beide gleichzeitig Symptome einer und derselben Erkrankung sein können. In meinen Experimenten spricht gegen die Ableitung des Icterus aus der Hämoglobinurie alles nur Denkbare. Der Icterus bei den Katzen ist in mehreren Fällen. unzweifelhaft das primäre, die Hämoglobinurie das secundäre; der Icterus nimmt im Verlaufe der Hämoglobinurie nicht zu sondern ab. Bei dem Hunde mit Hämoglobinurie trat überhaupt kein nachweisbarer Icterus auf, ebensowenig bei dem Kaninchen. Nach meiner Meinung mïsste auch, wenn Icterus als die Folge von Auflösung:

1) Ein Fall von Hämoglobinurie bei Typhusrecidiv. Detrtsches Archiv f. klin. Medicin. Bd. XII.

2) Ein Fall von Hämoglobinurie bei Scharlach. Deutsches Archiv f. klin. Medicin. Bd. XIII.

3) Eitner, Mehrere Fälle von Hämoglobinurie, hervorgerufen durch Einathmen von Arsenwasserstoff. Berl. klin. Wochenschr. 1880. No. 18.

4) Marchand, Ueber die Intoxication durch chlorsaure Salze. Virchow's Archiv. LXXIII.

5) Lichtheim, Periodische Hämoglobinurie. Volkmann'sche Vorträge. 134. - K üssner, Paroxysmale Hämoglobinurie. Deutsche med. Wochenschr. 1879. No. 37. 
grösserer Mengen von Blutkörperchen und Freiwerden von Blutfarbstoff, wofür ja die Hämoglobinurie der Ausdruck ist, anzusehen wäre, derselbe auch unfehlbar in jedem Falle von stärkerer Hämoglobinurie auftreten. Oder was für ein Grund sollte dafür existiren, dass unter denselben gegebenen Bedingungen das eine Mal sogenannter hämatogener Icterus auftritt, das andere Mal nicht?

In welchem Zusammenhange aber Icterus und Hämoglobinurie zu einander stehen, das bleibt durch meine Experimente vollkommen unaufgeklärt, und ich stehe nicht an, dies offen einzugestehen. Leider bleibt meine Arbeit dadurch ausserordentlich lückenhaft, aber mir bietet sich absolut kein Anhaltspunkt mehr, von dem aus ich diese offene Frage zur Entscheidung zu bringen hoffen könnte, so dass ich jetzt, nachdem ich mich lange Zeit vergebens damit abgemüht habe, eine Erklärung zu finden, mich darin ergeben muss, die gefundenen Thatsachen zu veröffentlichen und es glïcklicheren Zeiten oder Forschern zu überlassen, die Auflösung für diese räthselhafte Thatsache zu finden. 